\title{
Episodic Withdrawal Promotes Psychomotor Sensitization to Morphine
}

\author{
Patrick E Rothwell ${ }^{1,2}$, Jonathan C Gewirtz' and Mark J Thomas*,' \\ 'Graduate Program in Neuroscience and Departments of Neuroscience and Psychology, University of Minnesota, Minneapolis, MN, USA
}

\begin{abstract}
The relative intermittency or continuity of drug delivery is a major determinant of addictive liability, and also influences the impact of drug exposure on brain function and behavior. Events that occur during the offset of drug action (ie, acute withdrawal) may have an important role in the consequences of intermittent drug exposure. We assessed whether recurrent episodes of acute withdrawal contribute to the development of psychomotor sensitization in rodents during daily morphine exposure. The acoustic startle reflex-a measure of anxiety induced by opiate withdrawal — was used to resolve and quantify discrete withdrawal episodes, and pharmacological interventions were used to manipulate withdrawal severity. Startle potentiation was observed during spontaneous withdrawal from a single morphine exposure, and individual differences in initial withdrawal severity positively predicted the subsequent development of sensitization. Manipulations that reduce or exacerbate withdrawal severity also produced parallel changes in the degree of sensitization. These results demonstrate that the episodic experience of withdrawal during daily drug exposure has a novel role in promoting the development of psychomotor sensitization - a prominent model of drug-induced neurobehavioral plasticity. Episodic withdrawal may have a pervasive role in many effects of intermittent drug exposure and contribute to the development of addiction.

Neuropsychopharmacology (2010) 35, 2579-2589; doi:I0.1038/npp.20 I0. I34; published online I September 2010
\end{abstract}

Keywords: addiction; morphine; withdrawal; acoustic startle; individual differences; sensitization

\section{INTRODUCTION}

The development of drug addiction involves adaptations in brain function caused by chronic drug use (Hyman et al, 2006; Kalivas and O’Brien, 2008; Koob and Kreek, 2007; Koob and Volkow, 2010; Robinson and Berridge, 2003). A large body of preclinical evidence suggests that the impact of drug exposure on brain function and behavior depends critically on the pattern of administration, specifically whether drug exposure is continuous or intermittent (Breese et al, 2005a; Fitzgerald et al, 1996; Gao et al, 1998; Houshyar et al, 2003, 2004; Ibuki et al, 1997; Lichtblau and Sparber, 1981; Post, 1980; Skjei and Markou, 2003; Tjon et al, 1997). Human drug abuse is a fundamentally intermittent activity, routinely interrupted by periods of sleep or limited drug supply (Baker et al, 2004; Dole et al, 1966; Koob and Kreek, 2007), and rapid drug delivery promotes the development of addiction (Samaha and Robinson, 2005). In contrast, continuous modes of drug delivery, such as the nicotine patch or methadone maintenance, have low addictive liability and are used as

\footnotetext{
*Correspondence: Dr MJ Thomas, University of Minnesota, 6-145 Jackson Hall, 32 I Church St SE, Minneapolis, MN 55455, USA, Tel: +6 12624 4963, Fax: +6 12624 7910, E-mail: tmhomas@umn.edu ${ }^{2}$ Currrent address: Neuroscience Institute, Stanford University, Palo Alto, CA, USA

Received 27 May 20 I0; revised 26 July 2010; accepted 28 July 2010
}

therapeutic treatments to reduce withdrawal and craving (Dole et al, 1966; Henningfield and Keenan, 1993).

During intermittent drug administration, drug levels rise and fall dynamically over time. Although the onset of drug action is associated with rewarding effects, the offset of drug action generates a negative emotional state of withdrawal that includes symptoms of anxiety, irritability, and dysphoria (Koob and Volkow, 2010). Withdrawal is often associated with the termination of chronic drug exposure, but spontaneous signs of withdrawal can be detected after a single drug exposure in humans (Breiter et al, 1997; Kirby and Stitzer, 1993; Van Dyke and Byck, 1982) and rodents (Laulin et al, 1998; Rothwell et al, 2009). These episodes of 'acute withdrawal' represent an intrinsic feature of intermittent drug abuse (Baker et al, 2004; Dole et al, 1966) that contribute to some unique effects of intermittent drug exposure (Breese et al, 2005a, b; Houshyar et al, 2003, 2004). In human populations, individual differences in withdrawal severity are an important risk factor for the development of addiction (Piasecki et al, 2005), and intense withdrawal symptoms predict a greater response to subsequent drug exposure (Newton et al, 2003; Uslaner et al, 1999). In the present study, we have examined whether recurrent episodes of acute withdrawal contribute to a specific effect of intermittent morphine exposure: the development of psychomotor sensitization.

In rodents, the psychomotor-activating effects of most addictive drugs are progressively and persistently enhanced by repeated administration, a phenomenon known as 
psychomotor sensitization (Robinson and Becker, 1986; Stewart and Badiani, 1993). This change is accompanied by sensitization to the rewarding properties of drugs (Robinson and Berridge, 2003; Vezina, 2004) and increased mesolimbic dompaine release (Spanagel et al, 1993), as well as other adaptations in the mesolimbic dopamine system (Vanderschuren and Kalivas, 2000). This evidence suggests that the development of sensitization may model the intensification of drug craving in human addicts (Robinson and Berridge, 1993). Sensitization is induced by exposure to most abused drugs, as well as by stressful experience (Kalivas and Stewart, 1991), and is one of the most prominent and thoroughly studied models of long-lasting drug-induced neurobehavioral plasticity. Although tolerance is commonly observed after continuous exposure, sensitization to both the psychomotor-activating and rewarding properties of drugs is most robust following intermittent exposure (Hammer et al, 1997; Hope et al, 2005; King et al, 1992; Nelson and Ellison, 1978; Post, 1980; Reith et al, 1987; Russo et al, 2007; Shippenberg et al, 1988, 1996; Shippenberg and Heidbreder, 1995). Despite this extensive evidence, it remains unclear why intermittent drug exposure is so critical for generating sensitization.

While monitoring the development of psychomotor sensitization during daily morphine exposure in rats, we concurrently measured the severity of individual withdrawal episodes using the acoustic startle reflex, a validated index of anxiety in humans and animals (Davis et al, 2010) that is reliably elevated during withdrawal from acute opiate exposure (Cabral et al, 2009; Harris and Gewirtz, 2004; Kalinichev and Holtzman, 2003; Rothwell et al, 2009). Not only did the initial severity of withdrawal predict the eventual degree of psychomotor sensitization, but pharmacological manipulations that reduce or exacerbate withdrawal also caused parallel changes in the degree of sensitization. These results suggest a novel mechanism for the development of psychomotor sensitization and have important implications for understanding the differential impact of intermittent and continuous drug exposure on the development of addiction.

\section{MATERIALS AND METHODS}

\section{Subjects}

Male Sprague-Dawley rats (Harlan, Indianapolis, IN) were housed in groups of $4-5$, in metal cages with a 12-h light/ dark cycle (light on $0800-2000 \mathrm{~h}$ ) and free access to food and water except during testing. Rats were allowed to acclimate to housing conditions for 2 weeks after arrival, were gently handled for two consecutive days before any testing or drug treatment, and weighed $250-350 \mathrm{~g}$ at the beginning of each experiment. All procedures conformed to the National Institutes of Health Guide for the Care and Use of Laboratory Animals and were approved by the University of Minnesota Institutional Animal Care and Use Committee.

\section{Drugs}

Morphine sulfate was provided by the National Institute on Drug Abuse (Rockville, MD). Naloxone hydrochloride was obtained from Sigma (St Louis, MO). All drugs were dissolved in $0.9 \%$ saline and injected subcutaneously in a volume of $1 \mathrm{~mL}$ per kg body weight, except in Experiment 1, in which morphine was given intraperitonially. All drug doses are expressed as the weight of the salt.

\section{Acoustic Startle}

The apparatus for testing acoustic startle has been described previously (Engelmann et al, 2009; Rothwell et al, 2009). To acclimate animals to the testing procedure, acoustic startle was tested on each of two days before drug exposure. For each session, rats were placed in the startle chambers for a 5 -min acclimation period, and then presented with 40 startle stimuli (20 each at 95 or $105 \mathrm{~dB}$ in semi-random order) with a 30 -second inter-stimulus interval.

\section{Locomotor Activity}

As previously described (Ferguson et al, 2004), locomotor activity was monitored in clear plastic cages $\left(8.5^{\prime \prime} \times 17.5^{\prime \prime}\right.$ $\left.\times 9^{\prime \prime}\right)$ with a central insert $\left(2.5^{\prime \prime} \times 9^{\prime \prime} \times 9^{\prime \prime}\right)$ and pine shavings or ground corncob bedding on the floor. Each cage was placed in a metal frame containing five sets of infrared photobeams, which traversed the short axis of the cage $2^{\prime \prime}$ above the ground. A computer running custom software (Applied Concepts, Ann Arbor, MI) monitored the number of 'crossovers', defined by the successive interruption of beams on opposite ends of the cage. Crossovers were analyzed in 10-min bins and also summed across the entire experimental session. In Experiment 1, the day before the first drug exposure, rats were placed in activity monitors immediately after startle testing. After a 30-min habituation (which was used to measure the locomotor response to novelty - see Table 1), rats were injected with saline and remained in the activity monitors for $2 \mathrm{~h}$. In all experiments, this habituation procedure was also conducted the day before Morphine Challenge (see below).

\section{Experiment 1: Concurrent Measurement of Withdrawal Severity and Psychomotor Sensitization}

Using data from the habituation sessions for acoustic startle and locomotor activity, animals were matched into experimental groups with similar mean startle amplitudes and similar activity levels following saline injection. Daily morphine injections were given over the course of 6 days (Figure 1a), with a dosing regimen used in previous studies of morphine sensitization in rats (Kalivas and Duffy, 1987). The first day ('Initial Test') and last day ('Final Test') began with a baseline startle session, after which rats were transferred to the activity monitors. Around $30 \mathrm{~min}$ later, they were injected with either saline or morphine $(3.2 \mathrm{mg} /$ $\mathrm{kg}$ ); this moderate dose was used to avoid locomotor suppression produced by higher morphine doses (Babbini and Davis, 1972). Activity was monitored for $110 \mathrm{~min}$ before returning animals to the startle chambers for a test session $2 \mathrm{~h}$ after morphine injection, the time of peak startle potentiation following $3.2 \mathrm{mg} / \mathrm{kg}$ morphine (Harris and Gewirtz, 2004). The 4 days between the Initial and Final Test ('Intervening Days') began with baseline startle and $30 \mathrm{~min}$ habituation in the activity monitors. Rats were then injected with saline or a higher dose of morphine $(10 \mathrm{mg} / \mathrm{kg})$ that acutely suppresses locomotor activity (Babbini and Davis, 

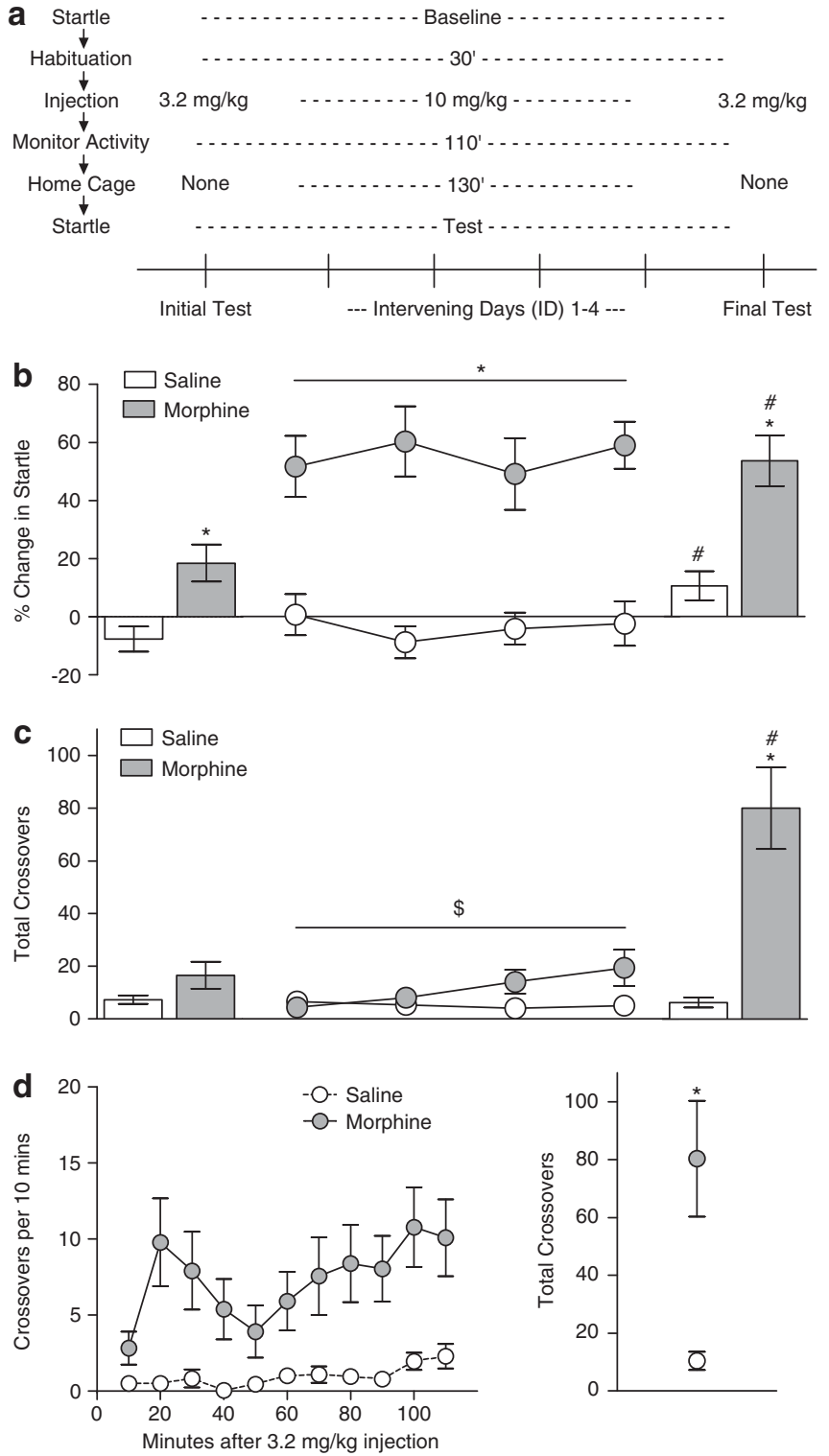

Figure I Concurrent measurement of withdrawal-potentiated startle and psychomotor sensitization. (a) Experimental timeline-locomotor activity and acoustic startle were tested after daily administration of morphine. The experimental procedures within each day and across days are laid out vertically and horizontally, respectively. Note that startle was tested at different time points after different doses of morphine ( $2 \mathrm{~h}$ after 3.2 vs $4 \mathrm{~h}$ after $10 \mathrm{mg} / \mathrm{kg}$ ). (b) Percent change in startle following injection of saline (open symbols, $n=24$ ) or morphine (filled symbols, $n=23$ ), vertically aligned with the timeline in panel (a). (c) Locomotor activity in the same group of animals. (d) Time course showing the locomotor response of both groups to Morphine Challenge (left) and cumulative response (right). *Significant difference between saline and morphine. " Significant difference between Final Test and Initial Test. \$Significant Group $\times$ Day interaction.

1972), but facilitates the development of sensitization (Ferguson et al, 2004; Kalivas and Duffy, 1987). They remained in the activity monitors for $2 \mathrm{~h}$ before being returned to the colony for two additional hours. Startle was then tested $4 \mathrm{~h}$ after morphine injection, the time of peak startle potentiation following $10 \mathrm{mg} / \mathrm{kg}$ morphine (Harris and Gewirtz, 2004; Rothwell et al, 2009). In an additional study (Supplementary Figure 1), we used a similar protocol,
Table I Correlations Between Behavioral Parameters in Experiment I

\begin{tabular}{|c|c|c|}
\hline Variables & Group & Statistics \\
\hline \multicolumn{3}{|c|}{ Withdrawal-potentiated startle on intervening days } \\
\hline IDI vs ID2 & Morphine & $r=0.47, p=0.029 *$ \\
\hline IDI vs ID3 & Morphine & $r=0.52, p=0.01 I^{*}$ \\
\hline IDI vs ID4 & Morphine & $r=0.47, p=0.024^{*}$ \\
\hline ID2 vs ID3 & Morphine & $r=0.47, p=0.027^{*}$ \\
\hline ID2 vs ID4 & Morphine & $r=0.57, p=0.005^{*}$ \\
\hline ID3 vs ID4 & Morphine & $r=0.40, p=0.061$ \\
\hline
\end{tabular}

Withdrawal severity and sensitization

ID I withdrawal vs composite sensitization

IDI withdrawal vs Final test sensitization

IDI withdrawal vs Challenge sensitization

IDI withdrawal vs Challenge

locomotion

$$
\begin{array}{ll}
\text { Morphine } & \boldsymbol{r}=\mathbf{0 . 5 0}, \boldsymbol{p}=\mathbf{0 . 0 1 6 *} \\
\text { Morphine } & \boldsymbol{r}=\mathbf{0 . 4 4}, \boldsymbol{p}=\mathbf{0 . 0 3 5} * \\
\text { Morphine } & \boldsymbol{r}=\mathbf{0 . 4 2 ,} \boldsymbol{p}=\mathbf{0 . 0 4 5 *} \\
\text { Saline } & r=-0.062, p=0.77
\end{array}
$$

Other factors

Escalation of withdrawal severity vs sensitization

IDI baseline startle vs sensitization

Response to novelty vs sensitization

Response to novelty vs Initial

Test locomotion

$$
\begin{array}{ll}
\text { Morphine } & r=0.21, p=0.33 \\
\text { Morphine } & r=0.21, p=0.33 \\
\text { Morphine } & r=0.01, p=0.97 \\
\text { Morphine } & \boldsymbol{r}=\mathbf{0 . 7 1}, \boldsymbol{p}=\mathbf{0 . 0 0 1 *}
\end{array}
$$

Abbreviation: ID, Intervening Day

Pearson's correlation coefficient is presented for each pair of variables in the indicated group; significant correlations are shown in bold. Sensitization in the morphine group was computed by subtracting the Initial Test locomotor response from the Final Test, Morphine Challenge, or their composite average. In the saline group, the locomotor response to Morphine Challenge was analyzed. Escalation of withdrawal severity represents the difference in withdrawal-potentiated startle on the Final Test versus the Initial Test. The response to novelty was measured during the first $30 \mathrm{~min}$ of the initial exposure to the activity monitor context.

but did not test startle on the Intervening Days. To determine the persistence of changes in locomotor activity following repeated morphine exposure, we conducted a 'Morphine Challenge' 7 days after the Final Test. Following a $30 \mathrm{~min}$ habituation period, all rats were injected with $3.2 \mathrm{mg} / \mathrm{kg}$ morphine and monitored for $2 \mathrm{~h}$, to compare the response to morphine following previous saline or morphine treatment.

\section{Experiment 2: Reducing Withdrawal by Decreasing the Interval Between Morphine Injections}

The purpose of this experiment was to attenuate acute withdrawal by giving morphine injections in rapid succession (Rothwell et al, 2009), and examine the impact on sensitization. Rats received cycles of four morphine injections $(10 \mathrm{mg} / \mathrm{kg}$ each), administered in the colony. Within each cycle, morphine injections were given $\sim 24 \mathrm{~h}$ apart, or every $3 \mathrm{~h}$ on a single day (Figure 3a). A separate 
control group received only saline injections, and an additional control group received a single morphine injection at the end of each cycle. All rats were given the same total number of injections, receiving saline when they were not scheduled to receive morphine. To control for circadian effects when giving morphine every $3 \mathrm{~h}$ (eg, 0900, 1200,1500 , and $1800 \mathrm{~h}$ ), daily injections were matched to these same times of day over the course of each cycle.

To verify the effectiveness of this manipulation, a preliminary study was conducted in which startle was measured on each of 2 days before the first injection, as well as $4 \mathrm{~h}$ after each injection across a single cycle. Because we were concerned that the mild stress associated with repeated startle testing (Roy et al, 2007) might obscure subtle differences between groups in the degree of sensitization, a separate group of rats received two cycles of morphine injections (separated by 3-4 days) with no startle testing. Sensitization was assessed in this latter group by Morphine Challenge 7 days after the end of the second injection cycle. After a $30 \mathrm{~min}$ habituation period, all rats were injected with $3.2 \mathrm{mg} / \mathrm{kg}$ morphine and monitored for $3 \mathrm{~h}$.

\section{Experiment 3: Enhancing Withdrawal Through Naloxone Treatment}

The purpose of this experiment was to use naloxone as a pharmacological tool to exacerbate the severity of withdrawal, and examine the impact on sensitization. A number of studies have shown naloxone can precipitate signs of withdrawal when administered $24 \mathrm{~h}$ after acute morphine exposure (Araki et al, 2004; Eisenberg, 1982; Gellert and Sparber, 1977; Jin et al, 2004; Parker and Joshi, 1998). We selected a dose $(2.5 \mathrm{mg} / \mathrm{kg})$ that produces startle potentiation and conditioned place aversion $24 \mathrm{~h}$ after a single morphine exposure (Rothwell et al, 2009). Rats received four daily injections of morphine $(10 \mathrm{mg} / \mathrm{kg})$ or saline in the colony. Each of these injections was followed $\sim 20 \mathrm{~h}$ later by exposure to naloxone $(2.5 \mathrm{mg} / \mathrm{kg})$ or saline (Figure 4a), an interval that allows spontaneous withdrawal to unfold normally following each morphine exposure, without interfering with the subsequent injection of morphine $\sim 4$ h later (Berkowitz et al, 1975). Sensitization was assessed by administering a Morphine Challenge ( 1 or $3.2 \mathrm{mg} / \mathrm{kg}$ ) to all rats in the activity monitors, 7 days after the last morphine injection, using the same procedure as Experiment 2 .

\section{Data Analysis}

Startle data were collapsed across both intensities (95/ $105 \mathrm{~dB}$ ) before statistical analysis (Harris and Gewirtz, 2004; Rothwell et al, 2009). In Experiments 1 and 2, we first conducted an analysis of variance to verify similar baseline startle amplitude between experimental groups; there were no differences in baseline startle between groups (Table 2 and data not shown). In Experiment 1, changes in startle following morphine administration were calculated as percent change from baseline on the same day (Walker and Davis, 2002). In Experiment 2, mean startle amplitude from the 2 days of testing before drug exposure was used to calculate percent change on each subsequent day. One rat from Experiment 1 and two rats from Experiment 2 were excluded from analysis because of unusually low baseline startle (ie, <10 units) (Harris et al, 2008; Lee and Davis, 1997). A composite index of sensitization was calculated in Experiment 1 by averaging the total number of crossovers on the Final Test and Morphine Challenge, and then subtracting the total number of crossovers on the Initial Test.

All data were analyzed using factorial analysis of variance, with repeated measures on within-subject factors. For main effects or interactions involving repeated measures, the Huynh-Feldt correction was applied to control potential violations of the sphericity assumption. Student-NewmanKeuls (SNK) post-hoc tests were conducted after significant main effects, whereas significant interactions were decomposed with tests for simple effects (Keppel, 1991). All statistical analyses were conducted using SPSS (version 13.0) with a type I error rate of $\alpha=0.05$ (two-tailed). Group sizes for each experiment are indicated in figure legends.

\section{RESULTS}

Experiment 1: Concurrent Measurement of Withdrawal Severity and Psychomotor Sensitization

The schematic in Figure la shows the experimental procedure within each day (laid out vertically), as well as across days (laid out horizontally). Significant withdrawalpotentiated startle was observed on the Initial Test after the very first exposure to a modest dose of morphine $(3.2 \mathrm{mg} / \mathrm{kg}$; Figure $1 \mathrm{~b}$, left $)\left(\mathrm{F}_{1,45}=11.70, p=0.001\right)$. Over the next four Intervening Days, consistent increases in startle were observed following each injection of $10 \mathrm{mg} / \mathrm{kg}$ morphine (main effect of Group: $\mathrm{F}_{1,43}=36.71, p<0.001$; Group $\times$ Day interaction: $\left.\mathrm{F}_{3,129}<1\right)$. There were also reliable individual differences between animals in the severity of this acute withdrawal state across the Intervening Days (Table 1). Comparing the degree of startle potentiation on the Final Test with the Initial Test, there were main effects of Group $\left(\mathrm{F}_{1,45}=28.7, p<0.001\right)$ and Day $\left(\mathrm{F}_{1,45}=19.9, p<0.001\right)$, but only a borderline interaction $\left(\mathrm{F}_{1,45}=2.20, p=0.14\right)$. The magnitude of startle potentiation in the morphine group was significantly increased on the Final Test relative to the Initial Test $\left(F_{1,22}=12.32\right.$, $p=0.002$ ), suggesting an escalation of withdrawal severity after repeated morphine exposure. However, there was also a small, but significant increase in startle potentiation in the saline group $\left(\mathrm{F}_{1,23}=7.45, p=0.012\right)$, contributing to the lack of a robust interaction. This latter finding may be related to a decrease in baseline startle levels that developed over the course of repeated daily testing (Table 2 ).

To confirm that the apparent escalation of withdrawal severity was not an indirect consequence of repeated startle testing, a separate group of animals was given the same drug treatment, but startle was not tested on the Intervening Days. Under these conditions we observed a significant Treatment $\times$ Day interaction $\left(F_{1,14}=18.23, p=0.001\right)$ (Supplementary Figure 1). The saline group showed no change in startle on the Initial or Final Test $\left(\mathrm{F}_{1,7}<1\right)$, whereas the morphine group still showed greater withdrawalpotentiated startle on the Final Test relative to the Initial Test $\left(\mathrm{F}_{1,7}=24.30, p=0.002\right)$. In this experiment, we also 
Table 2 Baseline Startle Values for Experiment I

\begin{tabular}{lcc}
\hline Session & Saline & Morphine \\
\hline Initial test & $32.5 \pm 2.7$ & $30.6 \pm 3.0$ \\
IDI & $32.0 \pm 2.8$ & $26.9 \pm 3.1$ \\
ID2 & $31.5 \pm 3.0$ & $26.3 \pm 3.0$ \\
ID3 & $29.7 \pm 3.0$ & $24.5 \pm 2.9$ \\
ID4 & $28.4 \pm 3.0$ & $24.4 \pm 3.1$ \\
Final test & $24.8 \pm 2.5$ & $22.9 \pm 2.7$ \\
\hline
\end{tabular}

Abbreviation: ID, Intervening Day.

Values shown are mean \pm SE for baseline startle (arbitrary units), measured before morphine or saline injection on each day. During the period of daily startle testing, there was a significant main effect of Day $\left(F_{5,215}=10.0\right.$, $p<0.00 \mathrm{I}$ ), indicating habituation of baseline startle amplitude across repeated daily testing (linear trend: $F_{1.43}=34.5, p<0.00 I$ ). However, there was no main effect of Group $\left(F_{1,43}<1\right)$, and no Group $\times$ Day interaction $\left(F_{5,215}<1\right)$, indicating both groups had similar baseline startle levels and exhibited a comparable degree of habituation across days.

found that escalation of withdrawal severity was no longer observed 7 days after the Final Test (Supplementary Figure 1).

There was a tendency for increased locomotor activity in the morphine group on the Initial Test (Figure 1c, left) $\left(\mathrm{F}_{1,45}=3.13, p=0.083\right)$. Over the next four Intervening Days there was a significant Group $\times$ Day interaction $\left(\mathrm{F}_{3,123}=3.34, p=0.044\right)$, indicating no change in activity in the saline group (linear trend: $F_{1,21}<1$ ), but a tendency towards an increase in the morphine group (linear trend: $\left.\mathrm{F}_{1,20}=3.88, p=0.063\right)$. The difference between groups was more pronounced on the Final Test, with the morphine group responding significantly more than the saline group $\left(\mathrm{F}_{1,45}=23.33, p<0.001\right)$ and also significantly more than on the Initial Test $\left(\mathrm{F}_{1,22}=19.10, p<0.001\right)$. This overall pattern was confirmed by a Group $\times$ Test interaction $\left(\mathrm{F}_{1,45}=19.72\right.$, $p<0.001)$. To examine the persistence of sensitization, both groups were challenged with morphine $(3.2 \mathrm{mg} / \mathrm{kg}) 1$ week after the Final Test. The locomotor response to Morphine Challenge had a biphasic temporal pattern (Figure 1d), with the morphine group responding significantly more than the saline group (Figure $1 \mathrm{~d}$, right) $\left(\mathrm{F}_{1,45}=12.39, p=0.001\right)$.

We next investigated the relationship between withdrawal severity and the development of psychomotor sensitization. The locomotor response of individual animals in the morphine group was similar on the Final Test and Morphine Challenge $(r=0.59, p=0.003)$, so both values were averaged together for each individual rat. The locomotor response on the Initial Test was subtracted from this average to provide a composite index of sensitization. We compared this value to the magnitude of withdrawalpotentiated startle on the first Intervening Day, as a measure of initial withdrawal severity following the first exposure to a high dose of morphine. There was a significant positive correlation between these two parameters in the morphine group (Figure 2$)(r=0.50, p=0.016)$, with more severe withdrawal predicting a higher degree of sensitization following repeated morphine injections. A similar relationship was observed when initial withdrawal severity was compared with the degree of sensitization on

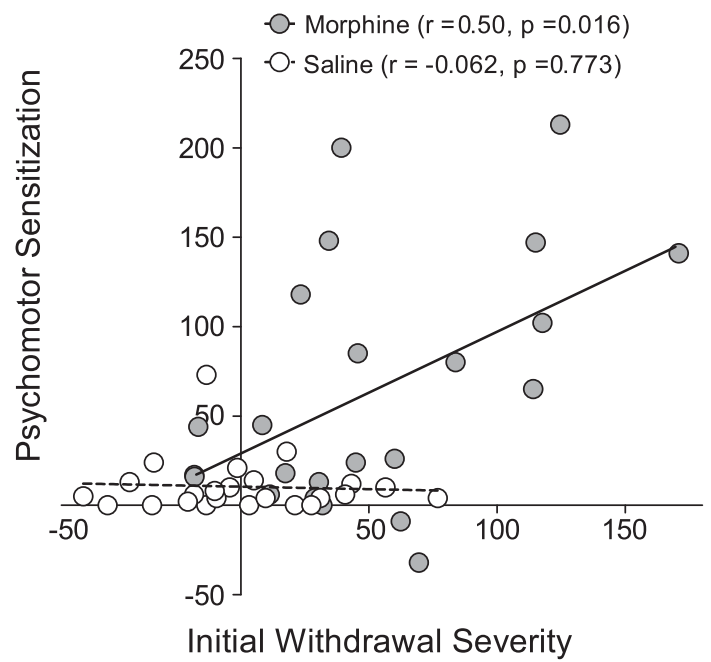

Figure 2 Correlation between initial withdrawal severity (ie, withdrawalpotentiated startle on first Intervening Day) and a composite index of sensitization (ie, average response across Final Test and Morphine Challenge minus Initial Test) in the morphine group, or the locomotor response to Morphine Challenge in the saline group.

either the Final Test or Morphine Challenge alone (Table 1). There was no relationship between startle potentiation on first Intervening Day and the locomotor response to Morphine Challenge in the saline group (Figure 2), demonstrating that the positive correlation in the morphine group is not an artifact of our testing procedure or analysis. There was also no predictive relationship between the degree of sensitization and the locomotor response to novelty, baseline startle on the first Intervening Day, or escalation of withdrawal severity across days (Table 1). These negative results demonstrate that initial withdrawal severity is an independent predictor of the development of sensitization. The locomotor response to novelty did correlate with the acute locomotor response to morphine on the Initial Test (Table 1), consistent with a previous report (Deroche et al, 1993).

\section{Experiment 2: Reducing Withdrawal by Decreasing the Interval between Morphine Injections}

We have previously shown that spontaneous withdrawalpotentiated startle, normally observed $4 \mathrm{~h}$ after $10 \mathrm{mg} / \mathrm{kg}$ morphine, is attenuated by a second injection of morphine given $3 \mathrm{~h}$ after the initial morphine exposure (Rothwell et al, 2009). We extended this manipulation to reduce cumulative withdrawal severity by administering cyles of morphine injections at intervals of 24 or $3 \mathrm{~h}$ (Figure $3 \mathrm{a}$ ). We first verified the effect of this manipulation on withdrawal severity by testing startle $4 \mathrm{~h}$ after each injection across a single cycle (Figure $3 \mathrm{~b}$ ). There was a significant GroupSession interaction $\left(\mathrm{F}_{18,348}=6.21, p<0.001\right)$, indicating robust startle potentiation following morphine injections at $24 \mathrm{~h}$ intervals, compared with the saline control group on the same day $(p<0.05$, SNK post-hoc). However, when morphine was administered at $3 \mathrm{~h}$ intervals, there were no differences from the saline control group $(p>0.38)$, 
a
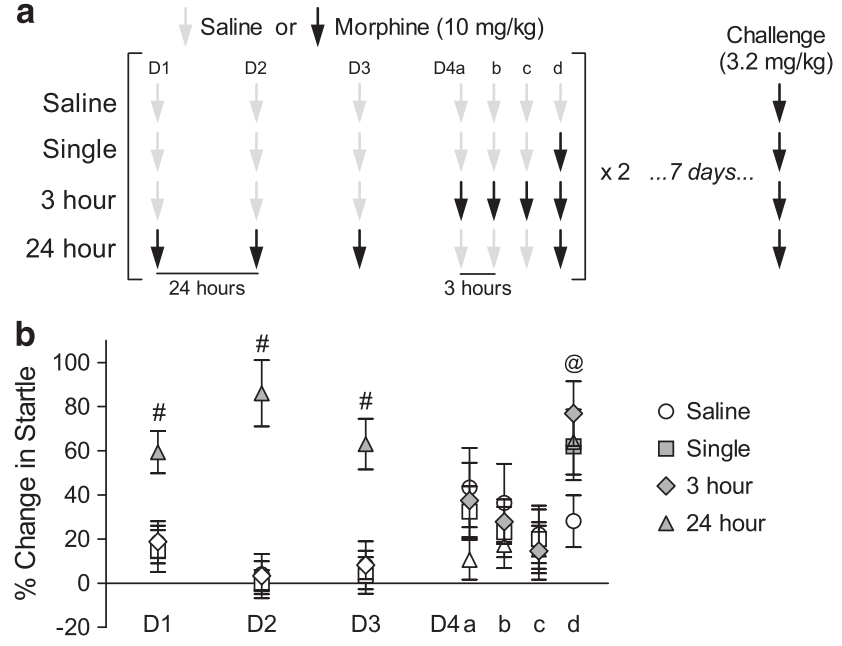

c
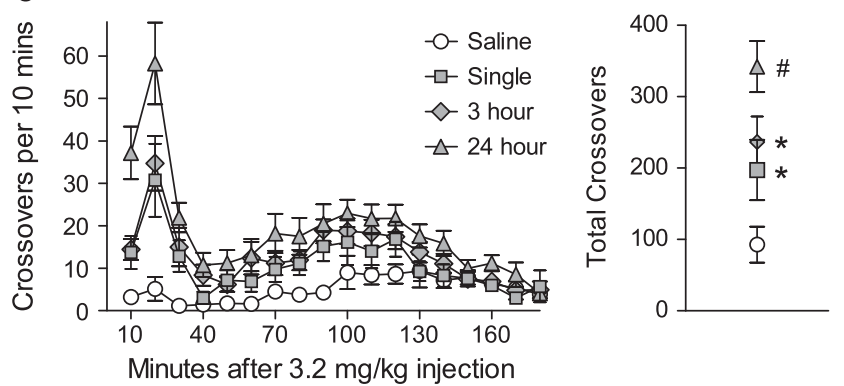

Figure 3 Reducing withdrawal decreases the degree of sensitization (a) Experiment timeline - cycles of four morphine injections $(10 \mathrm{mg} / \mathrm{kg})$ were delivered daily $(24 \mathrm{~h}$ ) or every $3 \mathrm{~h}$. Separate controls groups received one morphine injection at the end of each 3-h series ('Single') or were only injected with saline ('Saline'). (b) Startle tests conducted $4 \mathrm{~h}$ after each morphine injection across one injection cycle ( $n=17-18$ per group). In this panel only, symbol shading indicates a morphine injection was administered at the indicated time point. (c) Time course of locomotor activity (left) and cumulative response (right) to Morphine Challenge $(3.2 \mathrm{mg} / \mathrm{kg}$ ) I week following the end of two injection cycles ( $n=7-14$ per group). *Significant increase from saline. ${ }^{\#}$ Significant increase from all other groups. ${ }^{@}$ Tendency towards a difference between Saline and $3 \mathrm{~h}$ groups.

confirming that this manipulation effectively decreases overall withdrawal severity. The only exception was the 'terminal' withdrawal following the final 3-h injection, where there was a tendency towards increased startle in the $3 \mathrm{~h}$ group ( $p=0.098$, SNK post-hoc). To control for this terminal withdrawal episode, an additional group of animals were given a single morphine injection at the same time the 3-h group received their final injection of the day.

A separate group of animals given two cycles of this injection protocol were tested for sensitization 7 days after the end of the second cycle. The time course of the response to Morphine Challenge $(3.2 \mathrm{mg} / \mathrm{kg})$ is shown in Figure $3 \mathrm{c}$ (left), and analysis of the total number of crossovers (Figure 3c, right) indicated a significant effect of Group $\left(\mathrm{F}_{3,43}=9.93, \quad p<0.001\right)$. Daily injection of morphine (ie, every $24 \mathrm{~h}$ ) produced robust sensitization compared with repeated saline injection $(p<0.05$, SNK post-hoc). Animals receiving morphine injections every $3 \mathrm{~h}$ exhibited significantly less sensitization than the 24 -h group $(p<0.05$, SNK post-hoc). However, the 3 -h group still exhibited significant sensitization compared with the saline control
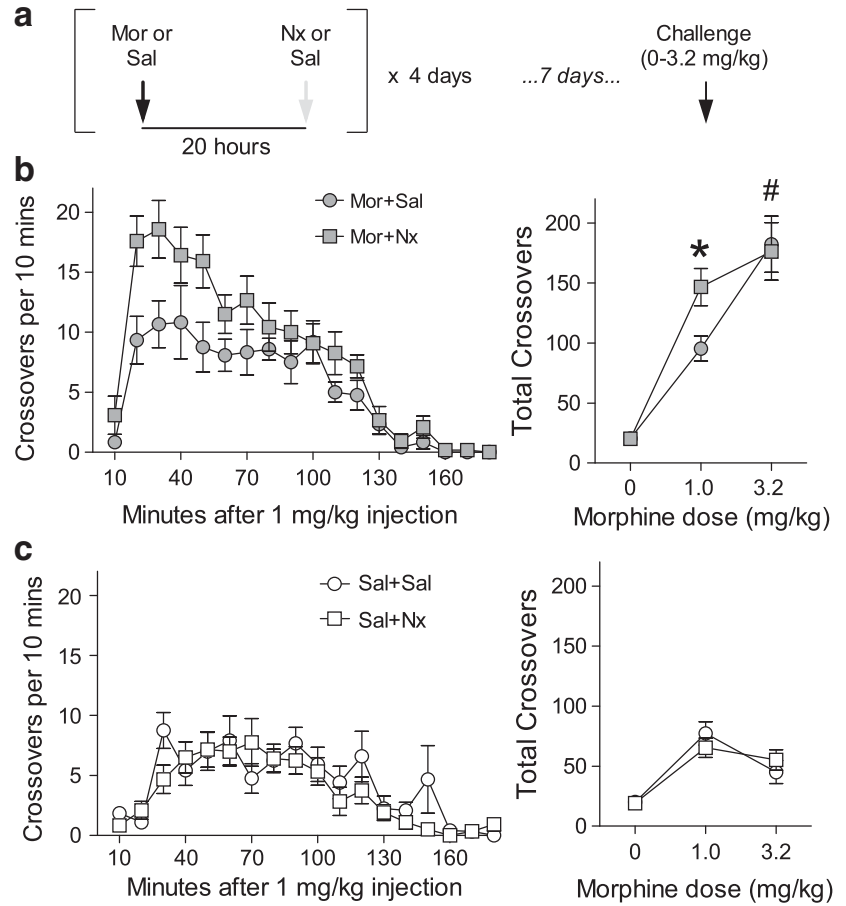

Figure 4 Exacerbating withdrawal severity enhances the degree of sensitization. (a) Experimental timeline-four daily injections of morphine (Mor, $10 \mathrm{mg} / \mathrm{kg}$ ) or saline (Sal) were followed $20 \mathrm{~h}$ later by injections of naloxone ( $\mathrm{Nx}, 2.5 \mathrm{mg} / \mathrm{kg}$ ) or Sal. (b) Time course of locomotor activity following Morphine Challenge (I mg/ $/ \mathrm{kg}$, left) and cumulative response to challenge with multiple doses (right) after Mor + Sal $(n=12)$ or Mor $+\mathrm{Nx}$ $(n=12)$. (c) Time course of locomotor activity following Morphine Challenge (I mg/kg, left) and cumulative response to challenge with multiple doses (right) after Sal +Sal $(n=12)$ or Sal $+\mathrm{Nx} \quad(n=12)$. *Significant difference between Mor-Nx and Mor-Sal. \#Significant main effect of Morphine.

group $(p<0.05$, SNK post-hoc). The terminal withdrawal episode likely contributes to the sensitization observed in the 3-h group, as the degree of sensitization was similar to the control group receiving a single morphine injection.

\section{Experiment 3: Exacerbating Withdrawal Through Naloxone Treatment}

Previous studies have shown that naloxone causes an array of behavioral, neural, and endocrine signs of withdrawal when administered $24 \mathrm{~h}$ after a single morphine exposure (Araki et al, 2004; Eisenberg, 1982; Gellert and Sparber, 1977; Jin et al, 2004; Parker and Joshi, 1998; Rothwell et al, 2009). Therefore, we administered naloxone $\sim 20 \mathrm{~h}$ after each morphine injection (Figure 4a) to precipitate an additional bout of withdrawal, thereby increasing overall withdrawal severity beyond the level of spontaneous withdrawal alone. Following challenge with $1 \mathrm{mg} / \mathrm{kg}$ morphine, analysis of variance indicated a significant Morphine $\times$ Naloxone interaction $\left(\mathrm{F}_{1,44}=7.89, \quad p=0.007\right)$. Naloxone administered after each daily morphine injection enhanced the response to subsequent Morphine Challenge (Figure $4 \mathrm{~b}) \quad\left(\mathrm{F}_{1,22}=7.56, p=0.012\right)$, whereas naloxone administered after daily saline injection had no effect (Figure $4 \mathrm{c})\left(\mathrm{F}_{1,22}<1\right)$. Following challenge with a higher 
dose of morphine $(3.2 \mathrm{mg} / \mathrm{kg})$, there was a significant main effect of Morphine $\left(\mathrm{F}_{1,74}=38.59, p<0.001\right)$, but no Morphine $\times$ Naloxone interaction $\left(F_{1,74}<1\right)$. No significant group differences were observed following saline challenge $(0 \mathrm{mg} / \mathrm{kg}) \quad(p>0.28)$. Combined morphine and naloxone treatment, therefore, increased sensitivity to a threshold dose of morphine, shifting the dose-response curve to the left - a defining feature of sensitization.

\section{DISCUSSION}

This study represents the first attempt to resolve individual episodes of withdrawal during daily morphine exposure and examine their contribution to the development of psychomotor sensitization. We document a correlation between the initial severity of acute withdrawal, indexed by potentiation of the acoustic startle reflex, and the development of psychomotor sensitization following repeated morphine exposure. Pharmacological manipulations that reduce or exacerbate withdrawal severity also caused parallel changes in the development of sensitization. These results identify a novel mechanism promoting the development of sensitization that may have a more general role in determining the behavioral and neurobiological impact of intermittent drug exposure.

Withdrawal states are classically associated with termination of chronic drug exposure, but in the present study, we found reliable and robust withdrawal-potentiated startle in the hours following individual exposures to morphine. Increases in the magnitude of the acoustic startle reflex are routinely observed during states of anxiety in rodents, as well as humans (Davis et al, 2010), and anxiety represents one hallmark symptom of drug withdrawal (Koob and Volkow, 2010). There were consistent individual differences between animals in the degree of startle potentiation, and this effect appeared to escalate in severity following repeated drug exposure, consistent with a broader literature showing the severity of withdrawal increases with repeated opiate exposure (Celerier et al, 2001; Harris and Gewirtz, 2005). Increases in the magnitude of withdrawalpotentiated startle were apparent on the Final Test in Experiment 1 following exposure to a moderate dose of morphine $(3.2 \mathrm{mg} / \mathrm{kg})$, but were not observed during repeated treatment with $10 \mathrm{mg} / \mathrm{kg}$ morphine, which likely reflects an upper limit on the degree of startle potentiation that can be detected during morphine withdrawal. However, the escalation of withdrawal severity across repeated morphine exposure did not correlate with the development of sensitization, and did not persist over a 7-day period following the last daily morphine injection. The relative transience of this effect does not preclude a more lasting contribution of conditioned withdrawal states to the persistence of addiction (Stinus et al, 2000).

A principal finding of the present study is that the initial severity of acute withdrawal, measured after the first exposure to a high dose of morphine, correlated with the development of psychomotor sensitization following repeated morphine exposure. This correlation suggests a predictive relationship in which intense withdrawal precedes the subsequent development of sensitization, consistent with clinical reports that withdrawal severity is an important risk factor for the development of addiction (Piasecki et al, 2005), and that intense withdrawal symptoms predict a greater response to subsequent drug exposure (Newton et al, 2003; Uslaner et al, 1999). It is possible that the correlation between withdrawal and sensitization indicates a general vulnerability to the behavioral effects of morphine mediated by a common underlying factor. For example, the rate of morphine metabolism may affect both the timing of the withdrawal response and the degree of sensitization. Rats that metabolize morphine relatively quickly or relatively slowly may show less robust startle potentiation $4 \mathrm{~h}$ after morphine injection, because morphine clearance occurs either sooner or later than this time point. Conversely, slower morphine metabolism (and thus higher morphine levels in the brain) would tend to promote more robust sensitization in a simple linear fashion. This would lead to a quadratic relationship between startle potentiation and sensitizationie, an 'inverted U' - with large startle potentiation corresponding to moderate sensitization (and an average rate of morphine metabolism), whereas the greatest degree of sensitization would be associated with less startle potentiation (due to slow metabolism). However, the observed relationship between startle potentiation and sensitization is linear rather than quadratic, and thus cannot be explained by this mechanism. Although individual differences in the pharmacokinetics of morphine metabolism may not explain our results, the notion that a common underlying factor mediates both withdrawal severity and sensitization is intriguing, as these facets of addiction are often considered independently and thought to be mediated by distinct neural circuitry.

The alternative scenario, for which greater support can be derived from our remaining experiments, is that recurrent episodes of acute withdrawal promote the development of sensitization. This conclusion is based upon pharmacological manipulations of withdrawal severity that also impact the development of sensitization. To reduce overall withdrawal severity, we administered a series of morphine injections in close temporal proximity, to produce 'quasicontinuous' delivery of morphine and attenuate spontaneous withdrawal (Rothwell et al, 2009). In addition to decreasing total withdrawal severity, this manipulation also produced less sensitization than morphine injections delivered every $24 \mathrm{~h}$, a result consistent with previous reports (Contet et al, 2008; Eitan et al, 2003; Vanderschuren et al, 1997). The fact that sensitization is reduced but still significant after quasi-continuous morphine delivery may be related to the 'terminal withdrawal' that occurs following the last morphine injection in each series, as a single morphine injection led to a comparable degree of sensitization as quasi-continuous delivery. The contribution of terminal withdrawal may explain why sensitization is not observed shortly after the termination of chronic drug exposure (Hammer et al, 1997; Russo et al, 2007), but then emerges following a period of abstinence (Aston-Jones and Harris, 2004; Trujillo et al, 2004).

An important consideration for the interpretation of our results is that the rate of drug delivery also impacts the development of psychomotor sensitization (Samaha and Robinson, 2005). Manipulations of the relative continuity of drug administration, such as that employed in Experiment 2, 
affect both the onset and offset of drug action, making it difficult to parse the relative contributions of these two events. To specifically manipulate drug offset, we took advantage of the fact that naloxone can precipitate signs of withdrawal when administered $24 \mathrm{~h}$ after acute morphine exposure (Araki et al, 2004; Eisenberg, 1982; Gellert and Sparber, 1977; Jin et al, 2004; Parker and Joshi, 1998; Rothwell et al, 2009). Daily administration of naloxone $\sim 20 \mathrm{~h}$ after each morphine exposure enhanced the degree of sensitization, increasing sensitivity to a threshold dose of morphine and shifting the dose-response curve to the left. The low dose of morphine used for challenge $(1 \mathrm{mg} / \mathrm{kg})$ does not acutely suppress locomotor activity (Babbini and Davis, 1972), ruling out the possibility that naloxone treatment impacts sensitization by affecting tolerance to locomotor suppression. To our knowledge, this is the first demonstration that a direct manipulation of withdrawal influences the development of sensitization, and supports the notion that events occurring during drug offset make important contributions to the impact of addictive drug exposure. This may help explain differences in addictive liability between cocaine and methylphenidate, which show similar rates of uptake in the human brain, but differ in their rate of clearance (Volkow et al, 2004).

Although our experiments focused on morphine, psychomotor sensitization is a common consequence of intermittent exposure to most abused drugs (Robinson and Berridge, 1993), and episodic withdrawal may also promote sensitization to other drug classes. Although withdrawal from some drugs (such as psychostimulants) is not associated with prominent physical signs, a negative emotional state develops during withdrawal from nearly all types of abused drugs, and relief from emotional distress provides powerful motivation for ongoing drug use (Baker et al, 2004; Koob and Volkow, 2010). The emotional components of withdrawal include dissociable signs of anxiety and dysphoria (Rothwell et al, 2009). Anxiety-like increases in startle magnitude are seen after acute exposure to morphine (Harris and Gewirtz, 2004), as well as nicotine (Engelmann et al, 2009), whereas dysphoria may be indicated by conditioned place aversions that develop with a delay following acute exposure to opiates (Bechara et al, 1995; Pain et al, 2008), cocaine (Ettenberg and Bernardi, 2007; Pliakas et al, 2001), and ethanol (Morse et al, 2000). Increased thresholds for intracranial self-stimulation are also a common feature of withdrawal from most abused drugs (Koob et al, 2004). As intermittent exposure facilitates psychomotor sensitization to many different drugs, future studies should examine whether episodic withdrawal promotes sensitization to drugs other than morphine, and whether sensitization is tied specifically to the anxiety-like component of withdrawal.

A variety of adaptations in the mesolimbic dopamine system are thought to underlie the development of psychomotor sensitization (Vanderschuren and Kalivas, 2000). For example, cellular adaptations in the ventral tegmental area may serve as a trigger for the development of sensitization (Carlezon and Nestler, 2002). It is intriguing to note that these adaptations are only observed after intermittent morphine exposure, and not following continuous exposure (Fitzgerald et al, 1996). The offset of opiate action has recently been shown to be a potent stimulus for synaptic plasticity in the spinal cord (Drdla et al, 2009). The development of psychomotor sensitization is associated with multiple forms of synaptic plasticity in the mesolimbic dopamine system (Kauer and Malenka, 2007), raising the possibility that the offset of drug action drives some of these forms of plasticity. Indeed, delayed administration of NMDA receptor antagonists attenuates both psychomotor sensitization and analgesic tolerance following daily morphine exposure (Kosten and Bombace, 2000; Marek et al, 1991), suggesting NMDA receptor activation during the offset of drug action (Schilstrom et al, 2006) may be involved in generating these forms of behavioral plasticity.

Intermittent opiate exposure produces a pattern of physiological changes that mirror the effects of chronic stress (Houshyar et al, 2003; Houshyar et al, 2004)changes not observed following continuous opiate exposure. Brain stress systems are activated during drug withdrawal (Koob and Volkow, 2010), and the recurrent engagement of these systems during episodic withdrawal may explain why intermittent drug exposure and stressful experience both cause sensitization (Kalivas and Stewart, 1991), as well as other common changes in brain function and behavior (Breese et al, 2005a; Fitzgerald et al, 1996; Houshyar et al, 2003, 2004; Kauer and Malenka, 2007). Although the brain circuits mediating withdrawal and sensitization are often considered independently, a number of established anatomical and physiological mechanisms could underlie interactions between them. For example, corticotropin-releasing factor (CRF) systems in the extended amygdala are prominently activated during withdrawal (Koob and Volkow, 2010), and these same CRF systems project to the ventral tegmental area (Rodaros et al, 2007), where CRF is released during stress (Wang et al, 2005). Release of CRF in the ventral tegmental area during acute withdrawal could facilitate NMDA receptor-dependent forms of plasticity that promote the development of sensitization (Borgland et al, 2009; Covington et al, 2008).

Although this study focused on the contribution of episodic withdrawal to the establishment of psychomotor sensitization, our results also have implications for understanding vulnerability to relapse. The expression of sensitized psychomotor activation has been associated with increased drug-seeking behavior in several studies (De Vries et al, 1998, 2002; Vezina, 2004), suggesting episodic withdrawal during intermittent drug exposure may also promote relapse vulnerability. In contrast, continuous drug delivery during a period of withdrawal has been shown to reduce drug-seeking behavior in animal models (Leri et al, 2007, 2004), consistent with the effectiveness of maintenance therapy for human drug addicts (Dole et al, 1966; Henningfield and Keenan, 1993). A role for episodic withdrawal in establishing vulnerability to relapse would complement evidence that spontaneous withdrawal may itself reinstate extinguished drug-seeking behavior (Shaham et al, 1996). Although the physical manifestations of withdrawal usually subside soon after the termination of chronic opiate exposure, emotional manifestations of withdrawal (such as increased anxiety and enhanced sensitivity to stress) can persist for weeks (Aston-Jones and Harris, 2004). This state of 'protracted withdrawal' may contribute to the persistent capacity of stress to reinstate drug-seeking 
following withdrawal from heroin self-administration (Shalev et al, 2001).

The expression of acute withdrawal has been implicated in the specific consequences of intermittent exposure to opiates and other drugs (Breese et al, 2005a, b; Houshyar et al, 2003, 2004), and the recurrent nature of withdrawal during intermittent drug use likely promotes the development of addiction (Baker et al, 2004; Dole et al, 1966). Our results add to this literature by demonstrating that episodic withdrawal also promotes the development of psychomotor sensitization, a prominent form of drug-induced neurobehavioral plasticity that may model the transition to compulsive drug abuse in human addicts (Robinson and Berridge, 2003). One important clinical implication of these results is that continuous opiate delivery for therapeutic purposes - such as maintenance therapy for addiction or the treatment of chronic pain-should not be interrupted, as this may facilitate the development and persistence of addiction. The specific role of episodic withdrawal in the development of psychomotor sensitization may thus have more widespread implications for understanding the impact of exposure to addictive drugs and the progression of addiction.

\section{ACKNOWLEDGEMENTS}

We thank Bonnie LaCroix, Jonathan Ehrich, Armin Jewell, Mihir Pendurkar, Michael Smet, and Bobby Wasem for technical assistance; Gail Towers for diligent animal husbandry; and members of the Thomas and Gewirtz labs for stimulating discussions. This work was supported by funding from the University of Minnesota Graduate School (to PER) and grants from NIDA (DA007234 and DA023750 to PER, DA019666 to MJT, and DA018784 to JCG), the Whitehall Foundation (to MJT), and NARSAD (to JCG).

\section{DISCLOSURE}

The authors declare that, except for income received from their primary employers, no financial support or compensation has been received from any individual or corporate entity over the past three years for research or professional service, and there are no personal financial holdings that could be perceived as constituting a potential conflict of interest.

\section{REFERENCES}

Araki H, Kawakami KY, Jin C, Suemaru K, Kitamura Y, Nagata M et al (2004). Nicotine attenuates place aversion induced by naloxone in single-dose, morphine-treated rats. Psychopharmacology (Berl) 171: 398-404.

Aston-Jones G, Harris GC (2004). Brain substrates for increased drug seeking during protracted withdrawal. Neuropharmacology 47(Suppl 1): 167-179.

Babbini M, Davis WM (1972). Time-dose relationships for locomotor activity effects of morphine after acute or repeated treatment. Br J Pharmacol 46: 213-224.

Baker TB, Piper ME, McCarthy DE, Majeskie MR, Fiore MC (2004). Addiction motivation reformulated: an affective processing model of negative reinforcement. Psychol Rev 111: 33-51.

Bechara A, Nader K, van der Kooy D (1995). Neurobiology of withdrawal motivation: evidence for two separate aversive effects produced in morphine-naive versus morphine-dependent rats by both naloxone and spontaneous withdrawal. Behav Neurosci 109: 91-105.

Berkowitz BA, Ngai SH, Hempstead J, Spector S (1975). Disposition of naloxone: use of a new radioimmunoassay. J Pharmacol Exp Ther 195: 499-504.

Borgland SL, Ungless MA, Bonci A (2009). Convergent actions of orexin/hypocretin and CRF on dopamine neurons: Emerging players in addiction. Brain Res 1314: 139-144.

Breese GR, Overstreet DH, Knapp DJ (2005a). Conceptual framework for the etiology of alcoholism: a 'kindling'/stress hypothesis. Psychopharmacology (Berl) 178: 367-380.

Breese GR, Overstreet DH, Knapp DJ, Navarro M (2005b). Prior multiple ethanol withdrawals enhance stress-induced anxiety-like behavior: inhibition by CRF1- and benzodiazepine-receptor antagonists and a 5-HT1a-receptor agonist. Neuropsychopharmacology 30: 1662-1669.

Breiter HC, Gollub RL, Weisskoff RM, Kennedy DN, Makris N, Berke JD et al (1997). Acute effects of cocaine on human brain activity and emotion. Neuron 19: 591-611.

Cabral A, Ruggiero RN, Nobre MJ, Brandao ML, Castilho VM (2009). GABA and opioid mechanisms of the central amygdala underlie the withdrawal-potentiated startle from acute morphine. Prog Neuropsychopharmacol Biol Psychiatry 33: 334-344.

Carlezon Jr WA, Nestler EJ (2002). Elevated levels of GluR1 in the midbrain: a trigger for sensitization to drugs of abuse? Trends Neurosci 25: 610-615.

Celerier E, Laulin JP, Corcuff JB, Le Moal M, Simonnet G (2001). Progressive enhancement of delayed hyperalgesia induced by repeated heroin administration: a sensitization process. J Neurosci 21: 4074-4080.

Contet C, Filliol D, Matifas A, Kieffer BL (2008). Morphine-induced analgesic tolerance, locomotor sensitization and physical dependence do not require modification of mu opioid receptor, cdk5 and adenylate cyclase activity. Neuropharmacology 54: 475-486.

Covington III HE, Tropea TF, Rajadhyaksha AM, Kosofsky BE, Miczek KA (2008). NMDA receptors in the rat VTA: a critical site for social stress to intensify cocaine taking. Psychopharmacology (Berl) 197: 203-216.

Davis M, Walker DL, Miles L, Grillon C (2010). Phasic vs sustained fear in rats and humans: role of the extended amygdala in fear vs anxiety. Neuropsychopharmacology 35: 105-135.

De Vries TJ, Schoffelmeer AN, Binnekade R, Mulder AH, Vanderschuren LJ (1998). Drug-induced reinstatement of heroin- and cocaine-seeking behaviour following long-term extinction is associated with expression of behavioural sensitization. Eur J Neurosci 10: 3565-3571.

De Vries TJ, Schoffelmeer AN, Binnekade R, Raaso H, Vanderschuren LJ (2002). Relapse to cocaine- and heroin-seeking behavior mediated by dopamine D2 receptors is time-dependent and associated with behavioral sensitization. Neuropsychopharmacology 26: 18-26.

Deroche V, Piazza PV, Le Moal M, Simon H (1993). Individual differences in the psychomotor effects of morphine are predicted by reactivity to novelty and influenced by corticosterone secretion. Brain Res 623: 341-344.

Dole VP, Nyswander ME, Kreek MJ (1966). Narcotic blockade. Arch Intern Med 118: 304-309.

Drdla R, Gassner M, Gingl E, Sandkuhler J (2009). Induction of synaptic long-term potentiation after opioid withdrawal. Science 325: 207-210.

Eisenberg RM (1982). Further studies on the acute dependence produced by morphine in opiate naive rats. Life Sci 31: 1531-1540.

Eitan S, Bryant CD, Saliminejad N, Yang YC, Vojdani E, Keith Jr D et al (2003). Brain region-specific mechanisms for acute morphine-induced mitogen-activated protein kinase modulation 
and distinct patterns of activation during analgesic tolerance and locomotor sensitization. J Neurosci 23: 8360-8369.

Engelmann JM, Radke AK, Gewirtz JC (2009). Potentiated startle as a measure of the negative affective consequences of repeated exposure to nicotine in rats. Psychopharmacology (Berl) 207: $13-25$.

Ettenberg A, Bernardi RE (2007). Effects of buspirone on the immediate positive and delayed negative properties of intravenous cocaine as measured in the conditioned place preference test. Pharmacol Biochem Behav 87: 171-178.

Ferguson SM, Thomas MJ, Robinson TE (2004). Morphineinduced c-fos mRNA expression in striatofugal circuits: modulation by dose, environmental context, and drug history. Neuropsychopharmacology 29: 1664-1674.

Fitzgerald LW, Ortiz J, Hamedani AG, Nestler EJ (1996). Drugs of abuse and stress increase the expression of GluR1 and NMDAR1 glutamate receptor subunits in the rat ventral tegmental area: common adaptations among cross-sensitizing agents. J Neurosci 16: 274-282.

Gao WY, Lee TH, King GR, Ellinwood EH (1998). Alterations in baseline activity and quinpirole sensitivity in putative dopamine neurons in the substantia nigra and ventral tegmental area after withdrawal from cocaine pretreatment. Neuropsychopharmacology 18: 222-232.

Gellert VF, Sparber SB (1977). A comparison of the effects of naloxone upon body weight loss and suppression of fixed-ratio operant behavior in morphine-dependent rats. J Pharmacol Exp Ther 201: 44-54.

Hammer Jr RP, Egilmez Y, Emmett-Oglesby MW (1997). Neural mechanisms of tolerance to the effects of cocaine. Behav Brain Res 84: 225-239.

Harris AC, Gewirtz JC (2004). Elevated startle during withdrawal from acute morphine: a model of opiate withdrawal and anxiety. Psychopharmacology (Berl) 171: 140-147.

Harris AC, Gewirtz JC (2005). Acute opioid dependence: characterizing the early adaptations underlying drug withdrawal. Psychopharmacology (Berl) 178: 353-366.

Harris AC, Rothwell PE, Gewirtz JC (2008). Effects of the NMDA receptor antagonist memantine on the expression and development of acute opiate dependence as assessed by withdrawalpotentiated startle and hyperalgesia. Psychopharmacology (Berl) 196: 649-660.

Henningfield JE, Keenan RM (1993). Nicotine delivery kinetics and abuse liability. J Consult Clin Psychol 61: 743-750.

Hope BT, Crombag HS, Jedynak JP, Wise RA (2005). Neuroadaptations of total levels of adenylate cyclase, protein kinase A, tyrosine hydroxylase, cdk5 and neurofilaments in the nucleus accumbens and ventral tegmental area do not correlate with expression of sensitized or tolerant locomotor responses to cocaine. J Neurochem 92: 536-545.

Houshyar H, Gomez F, Manalo S, Bhargava A, Dallman MF (2003). Intermittent morphine administration induces dependence and is a chronic stressor in rats. Neuropsychopharmacology 28: 1960-1972.

Houshyar H, Manalo S, Dallman MF (2004). Time-dependent alterations in mRNA expression of brain neuropeptides regulating energy balance and hypothalamo-pituitary-adrenal activity after withdrawal from intermittent morphine treatment. J Neurosci 24: 9414-9424.

Hyman SE, Malenka RC, Nestler EJ (2006). Neural mechanisms of addiction: the role of reward-related learning and memory. Annu Rev Neurosci 29: 565-598.

Ibuki T, Dunbar SA, Yaksh TL (1997). Effect of transient naloxone antagonism on tolerance development in rats receiving continuous spinal morphine infusion. Pain 70: 125-132.

Jin C, Araki H, Nagata M, Suemaru K, Shibata K, Kawasaki H et al (2004). Withdrawal-induced c-Fos expression in the rat centromedial amygdala $24 \mathrm{~h}$ following a single morphine exposure. Psychopharmacology (Berl) 175: 428-435.
Kalinichev M, Holtzman SG (2003). Changes in urination/ defecation, auditory startle response, and startle-induced ultrasonic vocalizations in rats undergoing morphine withdrawal: similarities and differences between acute and chronic dependence. J Pharmacol Exp Ther 304: 603-609.

Kalivas PW, Duffy P (1987). Sensitization to repeated morphine injection in the rat: possible involvement of A10 dopamine neurons. J Pharmacol Exp Ther 241: 204-212.

Kalivas PW, O'Brien C (2008). Drug addiction as a pathology of staged neuroplasticity. Neuropsychopharmacology 33: 166-180.

Kalivas PW, Stewart J (1991). Dopamine transmission in the initiation and expression of drug- and stress-induced sensitization of motor activity. Brain Res Brain Res Rev 16: 223-244.

Kauer JA, Malenka RC (2007). Synaptic plasticity and addiction. Nat Rev Neurosci 8: 844-858.

Keppel G (1991). Design and Analysis: A Researcher's Handbook 3rd edn. Prentice Hall: Englewood Cliffs, NJ, xiii p 594.

King GR, Joyner C, Lee T, Kuhn C, Ellinwood Jr EH (1992). Intermittent and continuous cocaine administration: residual behavioral states during withdrawal. Pharmacol Biochem Behav 43: $243-248$.

Kirby KC, Stitzer ML (1993). Opioid physical dependence development in humans: effect of time between agonist pretreatments. Psychopharmacology (Berl) 112: 511-517.

Koob G, Kreek MJ (2007). Stress, dysregulation of drug reward pathways, and the transition to drug dependence. Am J Psychiatry 164: 1149-1159.

Koob GF, Ahmed SH, Boutrel B, Chen SA, Kenny PJ, Markou A et al (2004). Neurobiological mechanisms in the transition from drug use to drug dependence. Neurosci Biobehav Rev 27: 739-749.

Koob GF, Volkow ND (2010). Neurocircuitry of addiction. Neuropsychopharmacology 35: 217-238.

Kosten TA, Bombace JC (2000). Prior and delayed applications of dizocilpine or ethanol alter locomotor sensitization to morphine. Brain Res 878: 20-31.

Laulin JP, Larcher A, Celerier E, Le Moal M, Simonnet G (1998). Long-lasting increased pain sensitivity in rat following exposure to heroin for the first time. Eur J Neurosci 10: 782-785.

Lee Y, Davis M (1997). Role of the hippocampus, the bed nucleus of the stria terminalis, and the amygdala in the excitatory effect of corticotropin-releasing hormone on the acoustic startle reflex. J Neurosci 17: 6434-6446.

Leri F, Sorge RE, Cummins E, Woehrling D, Pfaus JG, Stewart J (2007). High-dose methadone maintenance in rats: effects on cocaine self-administration and behavioral side effects. Neuropsychopharmacology 32: 2290-2300.

Leri F, Tremblay A, Sorge RE, Stewart J (2004). Methadone maintenance reduces heroin- and cocaine-induced relapse without affecting stress-induced relapse in a rodent model of poly-drug use. Neuropsychopharmacology 29: 1312-1320.

Lichtblau L, Sparber SB (1981). Opiate withdrawal in utero increases neonatal morbidity in the rat. Science 212: 943-945.

Marek P, Ben-Eliyahu S, Vaccarino AL, Liebeskind JC (1991). Delayed application of MK-801 attenuates development of morphine tolerance in rats. Brain Res 558: 163-165.

Morse AC, Schulteis G, Holloway FA, Koob GF (2000). Conditioned place aversion to the 'hangover' phase of acute ethanol administration in the rat. Alcohol 22: 19-24.

Nelson LR, Ellison G (1978). Enhanced stereotypies after repeated injections but not continuous amphetamines. Neuropharmacology 17: 1081-1084.

Newton TF, Kalechstein AD, Tervo KE, Ling W (2003). Irritability following abstinence from cocaine predicts euphoric effects of cocaine administration. Addict Behav 28: 817-821.

Pain L, Oberling P, Mainsongeon M, Moulinoux JP, Simonnet G (2008). Delayed aversive effects of high-dose fentanyl. Prevention by a polyamine-deficient diet. Behav Brain Res 190: 119-123. 
Parker LA, Joshi A (1998). Naloxone-precipitated morphine withdrawal induced place aversions: effect of naloxone at $24 \mathrm{~h}$ postmorphine. Pharmacol Biochem Behav 61: 331-333.

Piasecki TM, Sher KJ, Slutske WS, Jackson KM (2005). Hangover frequency and risk for alcohol use disorders: evidence from a longitudinal high-risk study. J Abnorm Psychol 114: 223-234.

Pliakas AM, Carlson RR, Neve RL, Konradi C, Nestler EJ, Carlezon Jr WA (2001). Altered responsiveness to cocaine and increased immobility in the forced swim test associated with elevated cAMP response element-binding protein expression in nucleus accumbens. J Neurosci 21: 7397-7403.

Post RM (1980). Intermittent versus continuous stimulation: effect of time interval on the development of sensitization or tolerance. Life Sci 26: 1275-1282.

Reith ME, Benuck M, Lajtha A (1987). Cocaine disposition in the brain after continuous or intermittent treatment and locomotor stimulation in mice. J Pharmacol Exp Ther 243: 281-287.

Robinson TE, Becker JB (1986). Enduring changes in brain and behavior produced by chronic amphetamine administration: a review and evaluation of animal models of amphetamine psychosis. Brain Res 396: 157-198.

Robinson TE, Berridge KC (1993). The neural basis of drug craving: an incentive-sensitization theory of addiction. Brain Res Brain Res Rev 18: 247-291.

Robinson TE, Berridge KC (2003). Addiction. Annu Rev Psychol 54: 25-53.

Rodaros D, Caruana DA, Amir S, Stewart J (2007). Corticotropinreleasing factor projections from limbic forebrain and paraventricular nucleus of the hypothalamus to the region of the ventral tegmental area. Neuroscience 150: 8-13.

Rothwell PE, Thomas MJ, Gewirtz JC (2009). Distinct profiles of anxiety and dysphoria during spontaneous withdrawal from acute morphine exposure. Neuropsychopharmacology 34: 2285-2295.

Roy V, Merali Z, Poulter MO, Anisman H (2007). Anxiety responses, plasma corticosterone and central monoamine variations elicited by stressors in reactive and nonreactive mice and their reciprocal F1 hybrids. Behav Brain Res 185: 49-58.

Russo SJ, Bolanos CA, Theobald DE, DeCarolis NA, Renthal W, Kumar A et al (2007). IRS2-Akt pathway in midbrain dopamine neurons regulates behavioral and cellular responses to opiates. Nat Neurosci 10: 93-99.

Samaha AN, Robinson TE (2005). Why does the rapid delivery of drugs to the brain promote addiction? Trends Pharmacol Sci 26: 82-87.

Schilstrom B, Yaka R, Argilli E, Suvarna N, Schumann J, Chen BT et al (2006). Cocaine enhances NMDA receptor-mediated currents in ventral tegmental area cells via dopamine D5 receptor-dependent redistribution of NMDA receptors. J Neurosci 26: 8549-8558.

Shaham Y, Rajabi H, Stewart J (1996). Relapse to heroin-seeking in rats under opioid maintenance: the effects of stress, heroin priming, and withdrawal. J Neurosci 16: 1957-1963.

Shalev U, Morales M, Hope B, Yap J, Shaham Y (2001). Timedependent changes in extinction behavior and stress-induced reinstatement of drug seeking following withdrawal from heroin in rats. Psychopharmacology (Berl) 156: 98-107.
Shippenberg TS, Emmett-Oglesby MW, Ayesta FJ, Herz A (1988). Tolerance and selective cross-tolerance to the motivational effects of opioids. Psychopharmacology (Berl) 96: 110-115.

Shippenberg TS, Heidbreder C (1995). Sensitization to the conditioned rewarding effects of cocaine: pharmacological and temporal characteristics. J Pharmacol Exp Ther 273: 808-815.

Shippenberg TS, Heidbreder C, Lefevour A (1996). Sensitization to the conditioned rewarding effects of morphine: pharmacology and temporal characteristics. Eur J Pharmacol 299: 33-39.

Skjei KL, Markou A (2003). Effects of repeated withdrawal episodes, nicotine dose, and duration of nicotine exposure on the severity and duration of nicotine withdrawal in rats. Psychopharmacology (Berl) 168: 280-292.

Spanagel R, Almeida OF, Shippenberg TS (1993). Long lasting changes in morphine-induced mesolimbic dopamine release after chronic morphine exposure. Synapse 14: 243-245.

Stewart J, Badiani A (1993). Tolerance and sensitization to the behavioral effects of drugs. Behav Pharmacol 4: 289-312.

Stinus L, Caille S, Koob GF (2000). Opiate withdrawal-induced place aversion lasts for up to 16 weeks. Psychopharmacology (Berl) 149: 115-120.

Tjon GH, Voorn P, Vanderschuren LJ, de Vries TJ, Michiels NH, Jonker AJ et al (1997). Delayed occurrence of enhanced striatal preprodynorphin gene expression in behaviorally sensitized rats: differential long-term effects of intermittent and chronic morphine administration. Neuroscience 76: 167-176.

Trujillo KA, Kubota KS, Warmoth KP (2004). Continuous administration of opioids produces locomotor sensitization. Pharmacol Biochem Behav 79: 661-669.

Uslaner J, Kalechstein A, Richter T, Ling W, Newton T (1999). Association of depressive symptoms during abstinence with the subjective high produced by cocaine. Am J Psychiatry 156: 1444-1446.

Van Dyke C, Byck R (1982). Cocaine. Sci Am 246: 128-141.

Vanderschuren LJ, Kalivas PW (2000). Alterations in dopaminergic and glutamatergic transmission in the induction and expression of behavioral sensitization: a critical review of preclinical studies. Psychopharmacology (Berl) 151: 99-120.

Vanderschuren LJ, Tjon GH, Nestby P, Mulder AH, Schoffelmeer AN, De Vries TJ (1997). Morphine-induced long-term sensitization to the locomotor effects of morphine and amphetamine depends on the temporal pattern of the pretreatment regimen. Psychopharmacology (Berl) 131: 115-122.

Vezina P (2004). Sensitization of midbrain dopamine neuron reactivity and the self-administration of psychomotor stimulant drugs. Neurosci Biobehav Rev 27: 827-839.

Volkow ND, Fowler JS, Wang GJ, Swanson JM (2004). Dopamine in drug abuse and addiction: results from imaging studies and treatment implications. Mol Psychiatry 9: 557-569.

Walker DL, Davis M (2002). Quantifying fear potentiated startle using absolute versus proportional increase scoring methods: implications for the neurocircuitry of fear and anxiety. Psychopharmacology (Berl) 164: 318-328.

Wang B, Shaham Y, Zitzman D, Azari S, Wise RA, You ZB (2005). Cocaine experience establishes control of midbrain glutamate and dopamine by corticotropin-releasing factor: a role in stressinduced relapse to drug seeking. J Neurosci 25: 5389-5396.

Supplementary Information accompanies the paper on the Neuropsychopharmacology website (http://www.nature.com/npp) 